\title{
Association between oral health literacy and dental outcomes among users of primary healthcare services
}

Fábio Luiz MIALHE(a)

Beatriz Loureiro SANTOS(a)

Fernanda Maria Rovai BADO(a)

Alcir José de OLIVEIRA JÚNIOR(a)

Gustavo Hermes SOARES(b)

(a) Universidade Estadual de Campinas

- Unicamp, Piracicaba Dental School,

Department of Health Sciences and

Pediatric Dentistry, Piracicaba, SP, Brazil.

(b) Universidade de São Paulo - USP, School of Dentistry, Forensic Dentistry and Community Health department, São Paulo, SP, Brazil.
Declaration of Interests: The authors certify that they have no commercial or associative interest that represents a conflict of interest in connection with the manuscript.

\section{Corresponding Author:}

Fábio Luiz Mialhe

E-mail: mialhe@unicamp.br

hitps://doi.org/10.1590/1807-3107bor-2022.vol36.0004

Submitted: February 1, 2021

Accepted for publication: June 2, 2021

Last revision: July 5, 2021

\begin{abstract}
This study aimed to investigate the association between Oral Health Literacy (OHL) and dental outcomes. A sample of 920 adults above 18 years of age living in areas covered by 10 Family Health Units (FHUs) in a large city in São Paulo state, Brazil, was included. OHL was assessed using the short-form Health Literacy in Dentistry Scale (HeLD-14). Data on sociodemographic factors, oral health, and general health were obtained through a structured questionnaire. The investigated outcomes "tooth loss" and "reason for the last dental appointment" were evaluated using self-reported data. Simple logistic regression models were used to analyze the associations between each independent factor and outcomes. Factors that presented a significance level of $\leq 0.20$ in the bivariate analysis were included in the hierarchical multiple logistic regression models. Participants with an education level up to high school, low OHL, and poor/fair self-rated oral health had 1.35 (95\%CI, 1.01-1.80), 1.48 (95\%CI, 1.12-1.95), and 1.46 (95\%CI, 1.11-1.92) times more probability to report missing teeth, respectively. Adults from families with lower monthly income, low OHL, and poor/fair self-rated oral health had 1.70 (95\%CI, 1.29-2.26), 1.89 (95\%CI, 1.42-2.51), and 1.73 (95\%CI, 1.30-2.30) times more chance, respectively, to have gone to the last dental appointment due to pain or caries. Adults with low OHL levels are more likely to have missing teeth and have gone to the last dental visit for pain, reinforcing the importance of OHL as an important determinant for promoting oral health.
\end{abstract}

Keywords: Oral Health; Health Literacy; Tooth Loss; Health Services.

\section{Introduction}

The field of Health Literacy (HL) has been increasingly examined by epidemiologists and clinical researchers because of its relevance to various health outcomes. The World Health Organization (WHO) considers HL an important determinant of health. ${ }^{1}$ Although there is no consensus about its definition, the Institute of Medicine report defines HL as "the degree to which individuals have the capacity to obtain, process, and understand the basic health information and services needed to make appropriate health decisions." ${ }^{2}$ The core concept of HL is based on the goal of enabling individuals to make informed decisions about their health and to control the determinants that affect their health. ${ }^{3}$ 
Applied to the field of dentistry, the concept of Oral Health Literacy (OHL) has been identified as a key factor in reducing oral disparities and promoting oral health. OHL is part of a myriad of factors that affect an individual's ability to make decisions regarding their oral health., ${ }^{4,5}$ Studies have shown that individuals with low levels of OHL, present higher prevalence rates of oral conditions, such as dental caries, missing teeth, and periodontal disease, in addition to worse self-rated oral health, irregular attendance to dental appointments, poor oral healthrelated quality of life, and greater deleterious oral habits. ${ }^{6-12}$ However, evidence from systematic reviews indicates inconclusive findings regarding these associations. ${ }^{13-15}$

Furthermore, OHL is a construct that influences the use of dental services. Studies showed that individuals with low levels of OHL were associated with searching for dental treatment only in cases of emergency and missing dental consultations. ${ }^{8,10}$ In contrast, patients with adequate levels of OHL had dental check-ups more frequently than their counterparts. ${ }^{6}$ Therefore, these findings need to be confirmed in other settings, with populations from different countries and using robust samples. ${ }^{13}$

This study aimed to investigate the association between OHL and the dental outcomes "tooth loss" and "reason for the last dental appointment" in a sample of Brazilian users of primary healthcare services. We hypothesized that OHL is a stronger predictor of self-reported missing teeth and reason for the last dental appointment than other contextual and oral health-related factors.

\section{Methodology}

A cross-sectional study was conducted from August 2018 to August 2019 with Brazilian users of primary healthcare services in a large city.

The research protocol was approved by the Research Ethics Committee of the Faculty of Dentistry of Piracicaba (CAAE: 58141316.8.0000.5418). Verbal and written informed consent was obtained from all participants.

A pilot study was conducted with 20 adults, and all participants presented a good understanding of the questionnaire. The sample size was calculated considering a test power of $80 \%(\beta=0.20)$, a significance level of $5 \%(\alpha=0.05)$, a percentage of response in the unexposed group (high OHL) of $30 \%$, and a minimum detectable odds ratio of 1.5 . The calculations were performed using EpiInfo statistical software. The minimum sample size required was 894 participants.

Initially, 10 Family Health Units (FHUs) in a large city in São Paulo state, Brazil, were randomly selected. Then, a total of 1000 individuals aged ${ }^{3} 18$ years were randomly invited by the community health workers (CHWs) of each FHU to participate in the study. Data were collected from participants' homes through an interview with three previously trained researchers accompanied by CHWs. The researchers went through a 2 -h training process, and the training was carried out by a researcher experienced in epidemiological surveys and with the use of the OHL instrument.

The outcome of tooth loss was assessed through the question, "have you had any of your teeth extracted/ removed due to pain or dental caries?" Responses were recorded as "yes" or "no." The reason for the last dental appointment was assessed through the question, "what was the reason that led you to your last dental appointment?" Responses were recorded as "dental caries/pain" or "others."

OHL was measured using the Brazilian version of the HL in Dentistry scale (HeLD-14), a 14-item tool that appraises seven contextual domains related to OHL (communication, understanding, receptivity, utilization, support, financial, and access). Response options were recorded using a 5-point Likert scale, ranging from "unable to do" (score 0) to "without any difficulty." Sum scores ranged from 0 to 56 , with higher values indicating better OHL. The variable was categorized as "low OHL" and "high OHL" based on a median split. ${ }^{16}$

A structured questionnaire was used to obtain data on sociodemographic and health factors. Variables were dichotomized as follows: sex (female or male), age (18-44 years or $>44$ years), marital status (married/cohabiting or single/divorced/ widowed), education (up to high school or high school/university), and family income (up to two 
Brazilian monthly minimum wages [BMMW] or $>2$ BMMW [1 BMMW $\approx$ US\$ 245.8] ). Self-rated oral health was evaluated by asking participants how they rated their oral health. Response options for both questions were dichotomized as poor/fair and good/very good/excellent.

\section{Statistical analysis}

The sample characteristics were reported using descriptive statistics. Simple logistic regression models were used to analyze the unadjusted associations of each independent factor with self-reported outcomes. Factors that presented a significance level of $<20 \%$ in the bivariate analysis were included in the hierarchical multiple logistic regression models. Independent variables were grouped into Level 1 (predisposing), Level 2 (enabling), and Level 3 (need) according to the model proposed by Andersen and Davidson (Figure). ${ }^{17}$ The entry of variables in multiple models followed the order of levels. Factors that presented a significance level of $\leq 5 \%$ remained in the model and were analyzed with the factors of the subsequent block. Variables with a significance level of $\leq 5 \%$ after adjustment remained in the final model. The fit of the models was analyzed using the Akaike information criterion (AIC) and $-2 \log$ L (log-likelihood). Analyses were conducted using the statistical software R. ${ }^{18}$.

\section{Results}

Of the 1000 individuals invited to participate in the research, 920 responded to the questionnaires (response of 93.6\%). The mean age of the sample was 43.20 years $( \pm 15.7)$. The majority of the participants were female (67.4\%), without a university degree (66\%), and married (86.2\%). The median HeLD-14 score was 40 (interquartile range: 30-48). Approximately $60 \%$ of the participants rated their oral health as good, very good, or excellent. The prevalence rate of self-reported missing teeth due to pain/caries was $40.2 \%$.

In the bivariate analysis, missing teeth was associated with lower education (OR, 1.50; 95\%CI: 1.13-2.00), low OHL level (OR, 1.66; 95\%CI: 1.28-2.17), and worse self-rated oral health (OR, 1.58; 95\%CI: 1.20-2.06). After the inclusion of these factors to the hierarchical multiple logistic regression model, adults with lower education, low OHL, and worse self-rated oral health were 1.35 (95\%CI: 1.01-1.80), 1.48 (95\%CI: 1.12-1.95), and 1.46 (95\%CI: 1.11-1.92) times more likely to report missing teeth due to pain or caries, respectively (Table 1).

The proportion of participants who reported pain or caries as the reason for their last dental appointment was $36.2 \%$. Family income (OR: 1.97, 95\%CI: 1.50-2.59), low OHL level (OR, 2.18; 95\%CI: 1.65-2.87), and worse self-rated oral health (OR, 2.02; $95 \% \mathrm{CI}$, 1.53-2.65) were significantly associated with the outcome of the last dental appointment in the bivariate analysis. In the final model, adults with low family income, low OHL, and worse self-rated oral health were 1.70 (95\% CI, 1.29-2.26), 1.89 (95\%CI: 1.42-2.51), and 1.73 (95\%CI: 1.30-2.30) times more likely to report pain or caries, respectively, as the reason for their last dental appointment compared to their counterparts (Table 2). The AIC values indicated a better fit of the final model than the empty model for both outcomes.
Level 1

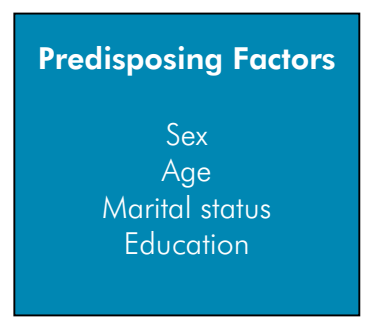

Level 2

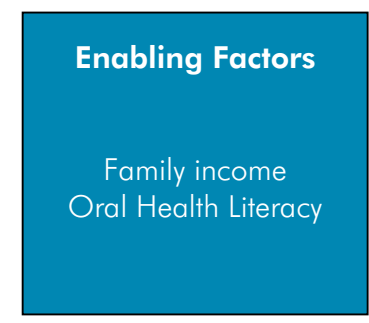

Level 3

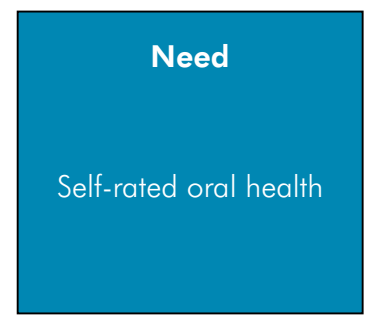

Figure. Framework employed in the analytical process (adapted from the model proposed by Andersen and Davidson, 1997). 
- Association between oral health literacy and dental outcomes among users of primary healthcare services

Table 1. Analysis (crude and adjusted) of the associations between tooth loss and independent variables.

\begin{tabular}{|c|c|c|c|c|c|c|c|}
\hline \multirow{3}{*}{ Variables } & \multirow{3}{*}{ n (\%) } & \multicolumn{2}{|c|}{ Tooth loss } & \multirow{2}{*}{$\begin{array}{l}\text { OR crude } \\
\text { (IC95\%) }\end{array}$} & \multirow{3}{*}{$p$-value } & \multirow{3}{*}{$\begin{array}{c}\text { OR adjusted } \\
\text { (IC95\%) }\end{array}$} & \multirow{3}{*}{$p$-value } \\
\hline & & No & *Yes & & & & \\
\hline & & n (\%) & n (\%) & & & & \\
\hline \multicolumn{8}{|l|}{ Level 1 Predisposing } \\
\hline \multicolumn{8}{|l|}{ Sex } \\
\hline Male & $300(32.6)$ & $189(63.0)$ & $111(37.0)$ & Ref & & & \\
\hline Female & $620(67.4)$ & $361(58.2)$ & $259(41.8)$ & $1.22(0.92-1.62)$ & 0.167 & & \\
\hline \multicolumn{8}{|l|}{ Age (years) } \\
\hline 18 to 44 & $516(56.1)$ & 309 (59.9) & $207(40.1)$ & Ref & & & \\
\hline$\geq 44$ & $404(43.9)$ & $241(59.6)$ & $163(40.4)$ & $1.01(0.77-1.32)$ & 0.944 & & \\
\hline \multicolumn{8}{|l|}{ Marital status } \\
\hline Married & $793(86.2)$ & $464(58.5)$ & $329(41.5)$ & $1.49(1.00-2.21)$ & & & \\
\hline Not Married & $127(13.8)$ & $86(67.7)$ & 41 (32.3) & Ref & 0.051 & & \\
\hline \multicolumn{8}{|l|}{ Education (years) } \\
\hline Up to high school & $607(66.0)$ & $343(56.5)$ & $264(43.5)$ & $1.50(1.13-2.00)$ & 0.005 & $1.35(1.01-1.80)$ & 0.047 \\
\hline Above high school & $313(34.0)$ & $207(66.1)$ & $106(33.9)$ & Ref & & Ref & \\
\hline \multicolumn{8}{|l|}{ Level 2 Enabling } \\
\hline \multicolumn{8}{|l|}{ Family income } \\
\hline Up to 2 BMMW & $457(49.7)$ & $267(58.4)$ & $190(41.6)$ & $1.12(0.86-1.46)$ & 0.404 & & \\
\hline Above 2 BMMW & $463(50.3)$ & $283(61.1)$ & $180(38.9)$ & Ref & & & \\
\hline \multicolumn{8}{|l|}{$\mathrm{OHL}$} \\
\hline Low & $465(50.5)$ & $250(53.8)$ & $215(46.2)$ & $1.66(1.28-2.17)$ & $<.001$ & 1.48 (1.12-1.95) & 0.005 \\
\hline High & $455(49.5)$ & $300(65.9)$ & $155(34.1)$ & Ref & & Ref & \\
\hline \multicolumn{8}{|l|}{ Level 3 Need } \\
\hline \multicolumn{8}{|l|}{ Self-rated oral health } \\
\hline Poor/fair & $365(39.7)$ & $194(53.2)$ & $171(46.8)$ & $1.58(1.20-2.06)$ & 0.001 & $1.46(1.11-1.92)$ & 0.007 \\
\hline $\begin{array}{l}\text { Good/very good/ } \\
\text { excellentexcellent }\end{array}$ & $555(60.3)$ & $356(64.1)$ & 199 (35.9) & Ref & & Ref & \\
\hline
\end{tabular}

*Reference category for the outcome variable. OR: odds ratio; $\mathrm{Cl}$ : confidence interval; BMMW: Brazilian monthly minimum wage; OHL: oral health literacy; AIC: Akaike information criterion. AIC (empty model) = 1241.94; -2Log L (empty model) $=1239.94 ; \mathrm{AIC}$ (final model $)=1220.41 ;-2 \log L($ final model $)=1210.41$.

\section{Discussion}

In this study, we conducted an exploratory investigation of the associations between OHL and dental outcomes in a large sample of Brazilian users of primary healthcare services. Our findings partially confirmed the initial hypothesis that low OHL is a stronger predictor of missing teeth and the reason for the last dental appointment than other contextual and oral health-related factors. Sociodemographic characteristics, such as education and family income, were also associated with the outcomes.
The proportion of older adults who reported at least one missing tooth due to pain or caries (40.2\%) was substantially lower than the prevalence rate of missing teeth observed in the 2015 São Paulo Oral Health Survey among adults aged $35-44$ years $(77 \%){ }^{19}$ These differences may be attributed to distinct sample characteristics and methodological differences related to how the outcome was assessed. Our study findings on the proportion of participants who had their last dental visit due to pain or caries (36.2\%) were consistent with the study findings reported by Tellez et al. ${ }^{20}$ in the USA and Devaraj and Eswar ${ }^{21}$ in India. The 2010 National Oral Health Survey 
Table 2. Analysis (crude and adjusted) of the associations between the reason for the last dental appointment and independent variables.

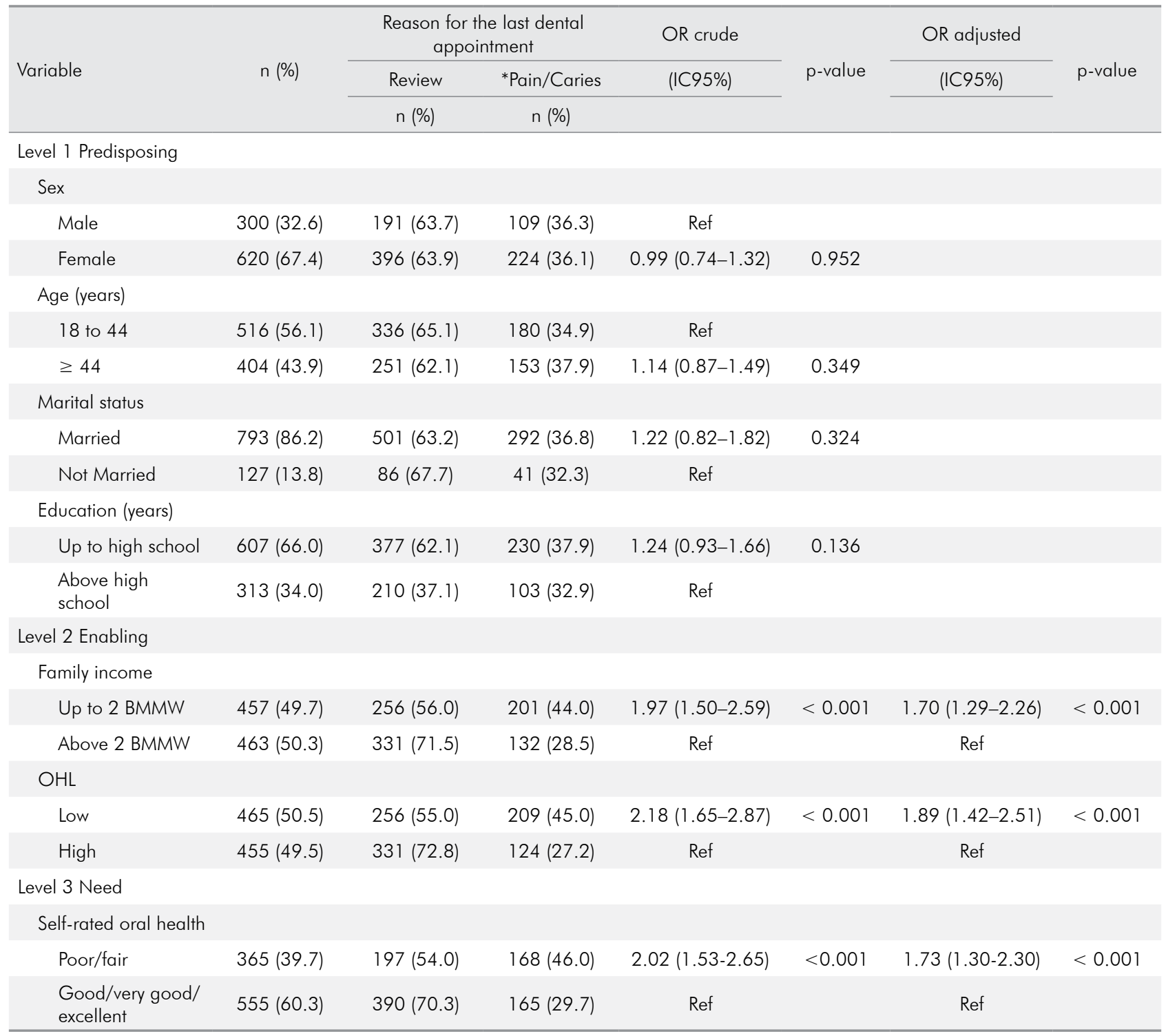

*Reference category for the outcome variable. OR: odds ratio; $\mathrm{Cl}$ : confidence interval; BMMW: Brazilian monthly minimum wage; OHL: oral health literacy; AIC: Akaike information criterion. *Reference category for the outcome variable. AIC (empty model) $=1206.35 ;-2 \mathrm{Log} L$ (empty model $)=1204.35 ;$ AIC (final model $)=1149.27 ;-2$ Log L (final model $)=1141.27$.

observed that $37 \%$ of Brazilian adults indicated pain or extraction as the reason for their previous dental appointment; however, these data cannot be directly compared to our findings because of differences in how the variable was categorized..$^{22}$

Based on our findings, low OHL was strongly associated with missing at least one tooth due to pain or caries among users of primary healthcare services. Similar findings have been reported in studies conducted with populations from the USA, ${ }^{10,23}$
Japan, ${ }^{11}$ and Belarus. ${ }^{24}$ Because untreated dental caries and periodontal disease are the main causes of tooth loss worldwide, the most favorable approach to stop the progress of these conditions and prevent tooth loss is early treatment. ${ }^{25}$ However, individuals with low OHL may not be equipped with the skills required to understand and apply health information, recognize the need for early treatment, and navigate the often complex health systems. It is hypothesized that individuals with adequate levels of OHL can 
identify early signs of oral conditions and are more likely to seek prompt treatment. These assumptions are supported by our findings of higher chances of reporting a last dental appointment motivated by pain or caries among individuals with low OHL.

We observed that individuals with low OHL were 1.89 times more likely to have had their previous dental appointment due to acute reasons than individuals with high OHL levels. Previous studies have demonstrated that the pattern of dental service utilization is associated with OHL levels. Batista et al. ${ }^{9}$ reported that Brazilian adults who sought dental treatment due to pain had a two-fold increased chance of presenting low OHL. Ueno et al. ${ }^{11}$ observed in Japanese adults that the higher the OHL levels, the more frequently they had a preventive dental checkup. Furthermore, the higher OHL was associated with visiting a dentist sometime in life among 12 year-old adolescents. ${ }^{26}$ Lower OHL levels were also associated with missed dental appointments. ${ }^{10}$ Conversely, studies found no association between OHL levels and the time of the last dental visit. ${ }^{8,27}$ In general, individuals with poor HL and OHL are those who least access health services or access it only in cases of emergency, as they may not have the skills needed to obtain, evaluate, and apply complex health information related to the importance of dental treatment and pathways to accessing dental services. ${ }^{28}$ Furthermore, these groups may face additional barriers related to OHL, such as financial hardship and unfriendly health systems.

It is important to note that our estimates of the associations between OHL and dental outcomes were adjusted using socioeconomic and self-rated oral health data. A growing body of evidence has demonstrated that income, education, and self-rated oral health are important predictors of OHL across different populations. ${ }^{29-31}$ The associations between tooth loss, education, and self-rated oral health have also been largely documented in the literature. ${ }^{32-35}$ Similar to our findings, previous studies indicate that income and self-rated oral health are important predictors of dental service utilization. ${ }^{12,36,37}$

In the past two decades, several instruments have been developed to measure population and individual levels of OHL. Nonetheless, the vast majority of these tools are exclusively focused on word recognition, ignoring the important dimensions of OHL. ${ }^{38}$ In this study, we employed a Brazilian validated version of the HeLD-14, a scale that evaluates the OHL in seven different domains: communication, understanding, receptivity, utilization, support, finance, and access. Thus, our findings provide a comprehensive and reliable assessment of OHL among a large sample of users of primary healthcare services. Furthermore, it is important to expand the limited understanding of OHL as an individual trait to consistently interpret our findings. From the perspective of the "health literacy environment," HL and OHL are conceptualized as structural components of the health system itself, a view that opens a new field of practical implications and potential interventions. ${ }^{39}$ For instance, our findings highlight the need to adopt processes, infrastructure, relationships, and policies in the primary healthcare sector that enable patients to understand, apply, access, and navigate health information and health services. This approach represents an important shift from the individualistic notion that patients are solely responsible for their deficit of skills related to health and emphasizes the importance of creating person-centered healthcare environments that are accessible and friendly for people with different levels of OHL. ${ }^{40}$ Ultimately, these changes may contribute to reducing inequalities in oral health. ${ }^{41}$

Our findings should be interpreted in light of the limitations of this study. Causal inference is precluded by the cross-sectional nature of the data. Self-reported data on missing teeth may be subject to recall bias. Although there is evidence that self-reporting is a reliable method to determine the number of teeth in population studies, ${ }^{42}$ it may not be as accurate as oral examinations performed by trained dentists. The findings may not be generalizable to nonurban populations and groups that do not use public primary healthcare services in Brazil.

\section{Conclusion}

Adults with low levels of OHL were more likely to report missing teeth and to have gone to their last dental appointment due to pain or caries. Socioeconomic factors and self-rated oral health were important predictors of missing teeth and the 
reason for the last dental appointment. Our findings highlight the importance of targeting OHL in oral health promotion strategies, in addition to creating person-centered healthcare environments.

\section{Acknowledgments}

This research received no specific grant from any funding agency in the public, commercial, or nonprofit sectors.

\section{References}

1. Kickbusch I, Pelikan JM, Apfel F, Tsouros AD. Health literacy: the solid facts. WHO Regional Office for Europe. Geneva: WHO; 2013.

2. US Department of Health and Human Services. Healthy People 2010: understanding and improving health. 2nd ed. Washington: US Government Printing Office; 2000.

3. Shanghai declaration on promoting health in the 2030 agenda for sustainable development. In Proceedings of the 9th Global Conference on Health Promotion, 2016 Nov 12-14, Shangai, China. Geneva: WHO; 2016.

4. Horowitz AM, Kleinman DV. Oral health literacy: a pathway to reducing oral health disparities in Maryland. J Public Health Dent. 2012;72 Suppl 1:S26-30. https://doi.org/10.1111/j.1752-7325.2012.00316.x

5. Institute of Medicine. Oral Health literacy: workshop summary. Washington: The National Academies Press; 2013.

6. Stein L, Pettersen KS, Bergdahl M, Bergdahl J. Development and validation of an instrument to assess oral health literacy in Norwegian adult dental patients. Acta Odontol Scand. 2015;73(7):530-8. https://doi.org/10.3109/00016357.2015.1007477

7. Baskaradoss JK. The association between oral health literacy and missed dental appointments. J Am Dent Assoc. 2016 Nov;147(11):867-74. https://doi.org/10.1016/i.adaj.2016.05.011

8. Burgette JM, Lee JY, Baker AD, Vann WF Jr. Is dental utilization associated with oral health literacy? J Dent Res. 2016 Feb;95(2):160-6. https://doi.org/10.1177/0022034515617457

9. Batista MJ, Lawrence HP, Sousa MD. Oral health literacy and oral health outcomes in an adult population in Brazil. BMC Public Health. 2017 Jul;18(1):60. https://doi.org/10.1186/s12889-017-4443-0

10. Baskaradoss JK. Relationship between oral health literacy and oral health status. BMC Oral Health. 2018 Oct;18(1):172. https://doi.org/10.1186/s12903-018-0640-1

11. Ueno M, Takeuchi S, Oshiro A, Kawaguchi Y. Relationship between oral health literacy and oral health behaviors and clinical status in Japanese adults. J Dent Sci. 2013;8(2):170-6. https://doi.org/10.1016/i.jds.2012.09.012

12. Bado FM, De Checchi MH, Cortellazzi KL, Ju X, Jamieson L, Mialhe FL. Oral health literacy, self-rated oral health, and oral health-related quality of life in Brazilian adults. Eur J Oral Sci. 2020 Jun;128(3):218-25. https://doi.org/10.1111/eos.12695

13. Firmino RT, Ferreira FM, Paiva SM, Granville-Garcia AF, Fraiz FC, Martins CC. Oral health literacy and associated oral conditions: A systematic review. J Am Dent Assoc. 2017 Aug;148(8):604-13. https://doi.org/10.1016/j.adaj.2017.04.012

14. Firmino RT, Ferreira FM, Martins CC, Granville-Garcia AF, Fraiz FC, Paiva SM. Is parental oral health literacy a predictor of children's oral health outcomes? Systematic review of the literature. Int J Paediatr Dent. 2018 Jul;28(5):459-71. https://doi.org/10.1111/ipd.12378

15. Firmino RT, Martins CC, Faria LD, Martins Paiva S, Granville-Garcia AF, Fraiz FC, et al. Association of oral health literacy with oral health behaviors, perception, knowledge, and dental treatment related outcomes: a systematic review and meta-analysis. J Public Health Dent. 2018 Jun;78(3):231-45. https://doi.org/10.1111/iphd.12266

16. Mialhe FL, Bado FM, Ju X, Brennan DS, Jamieson L. Validation of the health literacy in dentistry scale in Brazilian adults. Int Dent J. 2020 Apr;70(2):116-26. https://doi.org/10.1111/idj.12531

17. Andersen RM, Davidson PL. Ethnicity, aging, and oral health outcomes: a conceptual framework. Adv Dent Res. 1997 May;11(2):203-9. https://doi.org/10.1177/08959374970110020201

18. R Core Team. 2017. R: A language and environment for statistical computing. Vienna: R Foundation for Statistical Computing; 2017 [cited 2020 Nov 14]. Available from: https://www.R-project.org/

19. Pilotto LM, Celeste RK, Faerstein E, Slavutzky SM. Association between tooth loss and overweight/obesity among Brazilian adults: the Pró-Saúde Study. Braz Oral Res. 2014;28(1):1-6. https://doi.org/10.1590/1807-3107BOR-2014.vol28.0032

20. Tellez M, Kinner DG, Heimberg RG, Lim S, Ismail Al. Prevalence and correlates of dental anxiety in patients seeking dental care. Community Dent Oral Epidemiol. 2015 Apr;43(2):135-42. https://doi.org/10.1111/cdoe.12132

21. Devaraj C, Eswar P. Reasons for use and non-use of dental services among people visiting a dental college hospital in India: Aa descriptive cross-sectional study. Eur J Dent. 2012 Oct;6(4):422-7. https://doi.org/10.1055/s-0039-1698982

22. Brasil. SB Brasil 2010: National Oral Health Survey: main results. Brasília, DF: Ministério da Saúde; 2012.

23. Holtzman JS, Atchison KA, Macek MD, Markovic D. Oral health literacy and measures of periodontal disease. J Periodontol. 2017 Jan;88(1):78-88. https://doi.org/10.1902/jop.2016.160203 
Association between oral health literacy and dental outcomes among users of primary healthcare services

24. Blizniuk A, Ueno M, Zaitsu T, Kawaguchi Y. Association of oral health literacy with oral health behaviour and oral health status in Belarus. Community Dent Health. 2015 Sep;32(3):148-52.

25. Kassebaum NJ, Bernabé E, Dahiya M, Bhandari B, Murray CJ, Marcenes W. Global burden of severe tooth loss: a systematic review and meta-analysis. J Dent Res. 2014 Jul;93(7 Suppl):20-8S. https://doi.org/10.1177/0022034514537828

26. Neves ET, Lima LC, Dutra LD, Gomes MC, Siqueira MB, Paiva SM, et al. Oral health literacy, sociodemographic, family, and clinical predictors of dental visits among Brazilian early adolescents. Int J Paediatr Dent. 2021 Mar;31 (2):204-11. https://doi.org/10.1111/ipd.12660

27. Jamieson LM, Divaris K, Parker EJ, Lee JY. Oral health literacy comparisons between Indigenous Australians and American Indians. Community Dent Health. 2013 Mar;30(1):52-7. https://doi.org/10.1922/CDH_3025Jamieson06

28. Batterham RW, Hawkins M, Collins PA, Buchbinder R, Osborne RH. Health literacy: applying current concepts to improve health services and reduce health inequalities. Public Health. 2016 Mar;132:3-12. https://doi.org/10.1016/i.puhe.2016.01.001

29. Lopes RT, Neves ÉT, Dutra LD, Gomes MC, Paiva SM, Abreu MH, et al. Socioeconomic status and family functioning influence oral health literacy among adolescents. Rev Saúde Puública. 2020 Mar;54:30. https://doi.org/10.11606/s1518-8787.2020054001842

30. Mohammadi TM, Malekmohammadi M, Hajizamani HR, Mahani SA. Oral health literacy and its determinants among adults in Southeast Iran. Eur J Dent. 2018 Jul-Sep;12(3):439-42. https://doi.org/10.4103/ejd.ejd_429_17

31. VanWormer JJ, Tambe SR, Acharya A. Oral Health literacy and outcomes in Rural Wisconsin adults. J Rural Health. 2019 Jan;35(1):1221. https://doi.org/10.1111/irh.12337

32. Ferreira RC, Senna MI, Rodrigues LG, Campos FL, Martins AE, Kawachi I. Education and income-based inequality in tooth loss among Brazilian adults: does the place you live make a difference? BMC Oral Health. 2020 Sep;20(1):246. https://doi.org/10.1186/s12903-020-01238-9

33. Naorungroj S, Slade GD, Divaris K, Heiss G, Offenbacher S, Beck JD. Racial differences in periodontal disease and 10-year selfreported tooth loss among late middle-aged and older adults: the dental ARIC study. J Public Health Dent. 2017 Sep;77(4):372-82. https://doi.org/10.1111/iphd.12226

34. Haworth S, Shungin D, Kwak SY, Kim HY, West NX, Thomas SJ, et al. Tooth loss is a complex measure of oral disease: determinants and methodological considerations. Community Dent Oral Epidemiol. 2018 Dec;46(6):555-62. https://doi.org/10.1111/cdoe.12391

35. Meisel P, Holtfreter B, Völzke H, Kocher T. Self-reported oral health predicts tooth loss after five and ten years in a population-based study. J Clin Periodontol. 2018 Oct;45(10):1164-72. https://doi.org/10.1111/icpe.12997

36. Jayasvasti I, Htun KC, Peltzer K. Self-rated oral health status and social and health determinants among 35-65 year-old persons in one region in Myanmar: a cross-sectional study. Clin Cosmet Investig Dent. 2019 Nov;1 1:339-48. https://doi.org/10.2147/CCIDE.S227957

37. Hakeberg M, Wide Boman U. Dental care attendance and refrainment from dental care among adults. Acta Odontol Scand. 2017 Jul;75(5):366-71. https://doi.org/10.1080/00016357.2017.1317105

38. Ghaffari M, Rakhshanderou S, Ramezankhani A, Mehrabi Y, Safari-Moradabadi A. Systematic review of the tools of oral and dental health literacy: assessment of conceptual dimensions and psychometric properties. BMC Oral Health. 2020 Jul;20(1):186. https://doi.org/10.1186/s12903-020-01170-y

39. Dodson S, Good S, Osborne RH. Health literacy toolkit for low and middle-income countries: a series of information sheets to empower communities and strengthen health systems. New Delhi: WHO, Regional Office for South-East Asia; 2015.

40. Frosch DL, Elwyn G. Don't blame patients, engage them: transforming health systems to address health literacy. J Health Commun. 2014;19(sup2 Suppl 2):10-4. https://doi.org/10.1080/10810730.2014.950548

41. Marquillier T, Lombrail P, Azogui-Lévy S. [Social inequalities in oral health and early childhood caries: how can they be effectively prevented? A scoping review of disease predictors]. Rev Epidemiol Sante Publique. 2020;68(4):201-14. French. https://doi.org/10.1016/j.respe.2020.06.004

42. Margozzini P, Berríos R, Cantarutti C, Veliz C, Ortuno D. Validity of the self-reported number of teeth in Chilean adults. BMC Oral Health. 2019 Jun;19(1):99. https://doi.org/10.1186/s12903-019-0794-5 